\title{
Microscopic Study of the Aphanius dispar (Rüppell 1828) (Pisces: Cyprinodontidae) Ovary
}

\author{
Taher A. Ba-Omar and Aisha S. Al- Sulimani \\ Biology Department, College of Science, Sultan Qaboos University, P.O.Box 36, \\ Muscat, PC 123, OMAN \\ taher@squ.edu.om
}

Aphanius dispar (Rüppell 1828) (Pisces: Cyprinodontidae), is common and widely distributed in fresh and brackish water of the Middle East. Few studies were conducted on the structures of this fish organs. This study aimed to look at the structure of the ovary.

The fish were collected and transported into the Biology Department, Sultan Qaboos University. The fish were killed by placing them in ice for few minutes. Then they were dissected out for their gonads. The gonads have whitish color and are located in one side of the abdomen. The gonads were fixed in Karnovsky buffered with sodium cacodylate to a $\mathrm{pH}$ of 7.4 for four hours and then cut into small pieces. The tissue were washed in cacodylate buffer and then post-fixed in $1 \%$ aqueous solution of osmium tetroxide for 1 hour and dehydrated in a series of alcohol before embedding in Agar 100 resin. Semi and ultra-thin sections were cut using Reichert ultramicrotome. The semi-thin sections were stained with toluidine blue and the sections were examined using a Nikon 104 light microscope. The ultra-thin sections were stained with uranyl acetate and post-stained in lead citrate. They were examined under JEOL JEM -1230 TEM.

The ovary show different stages of the oocytes development. Three different stages of the development of the oocyte were seen; previtellogenesis, vitellogenesis and maturation (fig. A). Each oocyte is surrounded by follicle cells and by rough layers called zona radiata (fig. B). Follicle cells are irregular in shape with large nuclei. The Zona radiata (zona pollucida in mammals) is located between the follicle cells and the cytoplasm of the oocyte. It has a large number of pores (fig. C). The oocyte has a spherical nucleus, a number of smooth endoplasmic reticulum, Golgi complex and mitochondria (fig. D). 

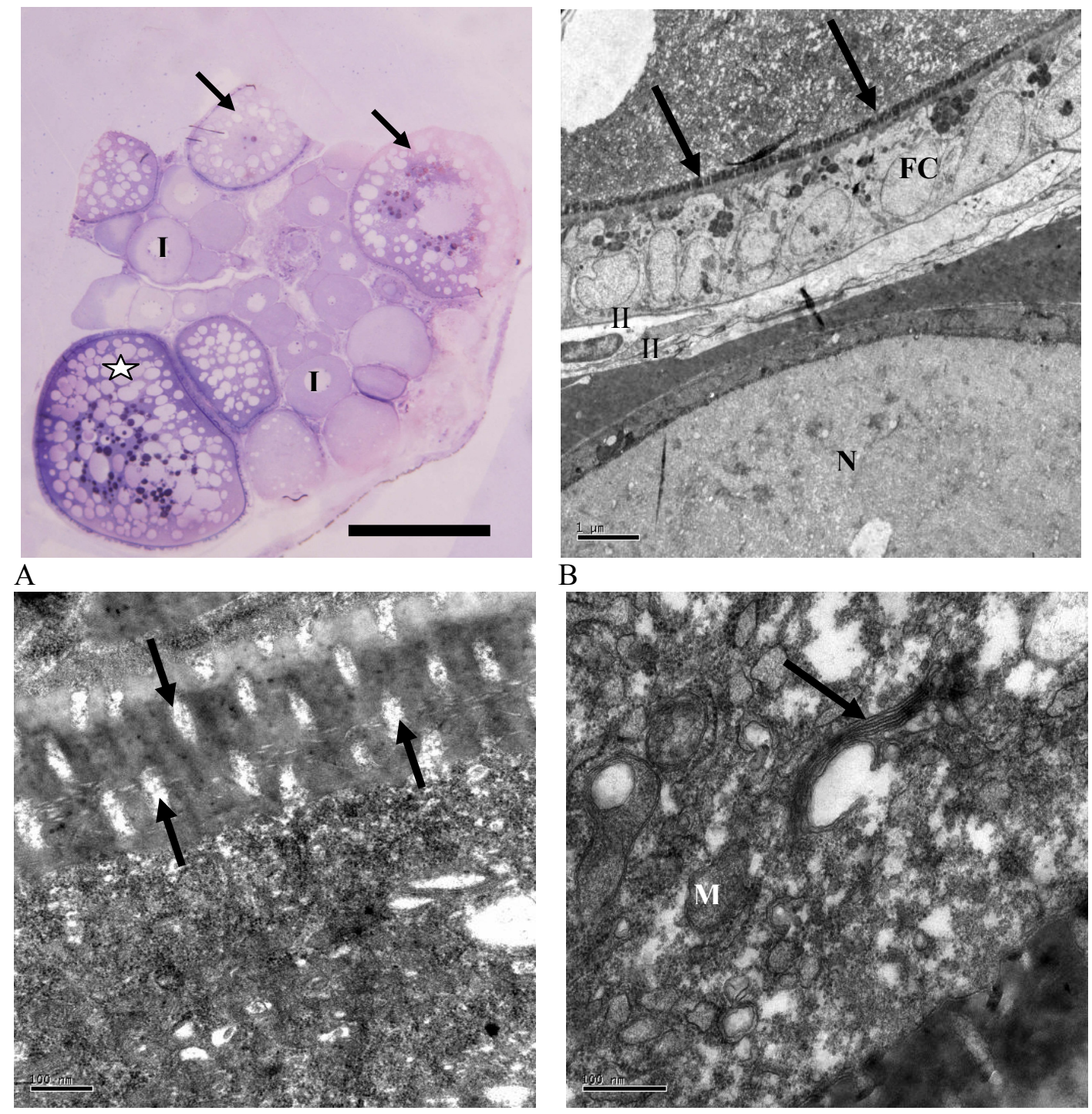

C

$\mathrm{D}$

Fig. A. Light micrograph of the ovary showing different developmental stages of oocyte; previtellogenesis (I), vitellogenesis (arrows) and maturation (star). Scale bar $=200 \mu \mathrm{m}$

Fig. B: Transmission electron micrograph showing two oocytes with follicle cells (FC) and the zona radiata (white arrow) that surround the oocyte. Scale bar=1um.

Fig. C: Transmission electron micrograph of zona radiata showing the pores (arrows). Scale bar $=100 \mathrm{~nm}$.

Fig. D: Transmission electron micrograph of an oocyte showing Golgi complex (white arrow) and mitochondria (M). Scale bar $=100 \mathrm{~nm}$. 